\title{
A Avaliação da Textualidade no Processo de Escrita Didático-Acadêmica: um estudo de caso
}

\author{
Débora Liberato Arruda HISSA*
}

\begin{abstract}
* Doutora em Linguística Aplicada. Professora do Programa de Pós-Graduação em Linguística Aplicada da Universidade Estadual do Ceará (PosLA/UECE), do Mestrado Profissional em Letras (Profletras) e da Especialização em Ensino de Língua Portuguesa (Espelp). Vice-coordenadora do Grupo de Pesquisa Linguagem, Ensino e Tecnologia (Lent). Contato: debora.arruda@uece.br.
\end{abstract}

\section{Resumo:}

Neste artigo, investigamos as estratégias de textualidade desenvolvidas na escrita didáticoacadêmica de material utilizado para os cursos de especialização na modalidade a distância. O corpus de pesquisa é constituído de 25 versões do texto-base do gênero webaula produzidas por 10 professores do curso de Licenciatura em Educação Profissional e Tecnológica (EPCT) do Instituto Federal de Educação, Ciência e Tecnologia do Ceará (IFCE). Discutimos o processo de produção do gênero webaula e analisamos a forma de textualizar e de realizar as operações linguísticas feitas pelos docentes. Ao final do estudo, vimos que os professores utilizam as operações de textualização - continuidade, progressão, não contradição, articulação - bem como a informatividade, heterogeneidade marcada como principais estratégias textualdiscursivas. Tais operações se dão a partir de uma articulação direta com o modo de produção colaborativo do material didático, a perspectiva de reversibilidade discursiva e a dupla audiência prevista pelos sujeitos para o texto.

\section{Palavras-chave:}

Estratégias de textualidade. Escrita didático-acadêmica. Produção de material didático.

Signum: Estudos da Linguagem, Londrina, v. 23, n. 1, p. 96-112, abr. 2020

Recebido em: 30/01/2020

Aceito em: 24/03/2020 


\title{
A Avaliação da Textualidade no Processo de Escrita Didático-Acadêmica: um estudo de caso
}

\author{
Débora Liberato Arruda Hissa
}

\section{INTRODUÇÃO}

Neste artigo, analisamos as estratégias de textualidade desenvolvida na escrita didática do material utilizado para os cursos de especialização na modalidade a distância. Compreendemos que elas são praticadas nos processos interacionais que o sujeito realiza para se comunicar em função de uma progressão/continuidade temática e dos recursos linguísticos empregados nessa atividade. O texto, em formato digital, ancora-se em um contexto situacional a partir da tomada de decisão do gênero e do discurso ${ }^{1}$ didático-acadêmico, tendo em vista que os textos analisados são destinados aos alunos do curso de especialização. Esse discurso produzido contém relações semânticas e pragmáticas que se dão entre os elementos no interior do próprio texto.

Para descrevermos as atividades linguísticas de textualidade, analisamos 25 versões de textos-base escritos por 10 professores do curso de Licenciatura Educação Profissional e Tecnológica (EPCT) do Instituto Federal de Educação, Ciência e Tecnologia do Ceará (IFCE), bem como as interferências escritas por outros dois sujeitos (designer e revisor textual) que colaboram com o professor na produção do material didático. Nossa intenção é perceber como a textualização é avaliada pelos sujeitos durante o processo didático de produção colaborativa de um gênero como a webaula e refletir sobre a forma de textualizar e de realizar as estratégias linguísticas na produção escrita do material didático para a Educação a Distância (EaD).

A fim de atingirmos o nosso objetivo de pesquisa, fizemos um estudo de caso no IFCE, norteado por autores como Val (1999), Matêncio (2002), Marcuschi (2008) e Cavalcante (2014). Escolhemos esta instituição porque ela dispõe de uma equipe multidisciplinar que produz de forma colaborativa o material didáticoacadêmico, tanto em modelo impresso como em formato digital. Este material é destinado aos cursos na modalidade a distância. Ao analisar o processo de produção colaborativo, vimos que, no primeiro momento, o trabalho da equipe multidisciplinar segue um fluxo de editoração semelhante ao de produção de livros didáticos. Já em um segundo momento, percebemos que há diferenças entre esses processos de produção. Uma diferença que nos chamou a atenção trata-se da forma de avaliação das estratégias de textualidade presentes no textobase do material didático. Ela é feita por meio de interferências textuais marcadas no texto e revelam a concepção que os sujeitos, que participam da equipe multidisciplinar (professores, designers e revisores textuais) têm sobre a escrita de um texto didático-acadêmico como a webaula, por exemplo.

Essas interferências acontecem da seguinte forma: logo que o texto-base de uma disciplina de um curso de EaD é finalizado pelo professor especialista, ${ }^{2}$ ele segue para outros sujeitos que irão lê-lo, avaliá-lo e/ou reescrevê-lo a partir de uma constante interlocução escrita feita em versões desse mesmo texto-base.

\footnotetext{
${ }^{1}$ Entendemos discurso com base nas premissas de Fiorin (2012, p. 146). Para Fiorin, o discurso é um objeto linguístico e um objeto histórico. Isso significa que ele é uma construção linguística gerada por um sistema de regras que define sua especificidade. O texto seria, assim, a manifestação de um discurso, por isso o texto pressupõe o discurso. Ambos são produtos da enunciação, embora sejam diferentes quanto ao modo de existência semiótica. O texto é a realização do discurso por meio de sua manifestação.

2 Professor especialista, também conhecido como professor conteudista no IFCE, é o docente responsável pela escrita do conteúdo de uma determinada disciplina dos cursos de EaD (tanto de graduação como de pós-graduação).
} 
As interlocuções, por sua vez, seguem um percurso cheio de idas e vindas de versões do material didático, composto de aulas (no impresso) e webaulas (na web), que envolvem diferentes sujeitos, cada um em sua área específica e com uma função determinada dentro do processo de produção. As avaliações e interferências feitas pelos colegas da equipe de produção no texto-base dão início a um processo de negociação de sentidos no próprio texto didático, e podem ser lidas e vistas por todos os sujeitos que produzem o texto.

Nas próximas seções, apresentamos o processo de escrita do material didático e o modo de avaliação da textualidade, que acontece tanto mediado pelas novas tecnologias quanto orquestrado pela sucessão de interferências no texto-base.

\section{Estratégias Linguísticas para a Avaliação da Textualidade de Material Didático}

Antes de conhecermos as estratégias linguísticas percebidas na validação do material didático destinado aos alunos que estudam na modalidade a distância, é importante compreender as etapas por que passa o textobase. Primeiramente o professor conteudista escreve individualmente a primeira versão do material, no formato digital (Word), e essa versão constitui, como a equipe multidisciplinar chama no processo de produção colaborativa, o conteúdo bruto do texto-base que está sendo desenvolvido. Nesse texto, como em qualquer outro, o professor que elabora o material usa de estratégias de textualidade para garantir a inteligibilidade do seu escrito. Em seguida, o texto-base é encaminhado para o designer educacional (DE), ${ }^{3}$ que fará a primeira avaliação e posterior validação do texto. Dependendo da avaliação feita pelo designer, que se dá por meio de interlocuções e interferências no texto-base, o material didático ou segue para o revisor textual ou retorna para o professor conteudista. O contato de cada sujeito com o texto gera novas interlocuções e interferências, as quais serão aceitas ou não pelos sujeitos. Essa negociação de sentido é mediada e orquestrada pelo designer educacional, como veremos nos exemplos destacados neste artigo.

Ao final do processo de produção, têm-se várias versões do texto em que são discutidos, de forma intuitiva pelos sujeitos, aspectos sobre a textualidade de um texto didático-acadêmico que será tanto impresso e distribuído nos polos de EaD como publicado no Ambiente Virtual de Aprendizagem (AVA) no formato do gênero webaula. ${ }^{4} \mathrm{Em}$ nosso estudo, identificamos as seguintes estratégias de textualização e de intervenção feitas pelos docentes que escrevem material didático (da versão impressa até a webaula) para os cursos de especialização no IFCE: a interlocução direta, a focalização, a continuidade, a articulação, a progressão temática, a não contradição, a informatividade e a heterogeneidade constitutiva. Todos estes fatores que garantem a textualidade foram observados nas validações feitas pelos sujeitos que produzem o material didático. Elas foram feitas a partir de interlocuções escritas por meio de caixas de comentários do Word ou dentro do próprio texto-base.

Para fim de análise da escrita colaborativa, neste artigo consideramos as metarregras da continuidade, da progressão, da não contradição e da articulação (CHAROLLES, 1978); o fator de textualidade informatividade (VAL, 1999) e a heterogeneidade constitutiva (AUTHIER-REVUZ, 1990), como operações de textualidade empreendidas pelos vários produtores do texto de uma webaula. Sendo assim, é possível identificar, já na primeira versão do texto-base, a ocorrência de operações de textualidade realizadas pelo professor conteudista, como primeiro produtor do texto. Sabemos que essas operações permeiam todas as fases de produção colaborativa em maior ou menor grau; no entanto, a análise da adequação, ou mesmo da

\footnotetext{
${ }^{3}$ Especialista que transpõe didaticamente o conteúdo bruto do texto da webaula para a versão multimodal, com acréscimos e adaptações de recursos hipertextuais, interativos, icônicos e multimídia.

${ }^{4}$ Para este estudo, tomamos a webaula como o principal material didático para a modalidade a distância, ainda que saibamos que, no caso do IFCE, há também a versão impressa do material, em formato de livro acadêmico, que é distribuído nos polos de EaD.
} 
ausência de uso dessas operações, acontece propriamente depois da fase de escrita individual, uma vez que, a partir da segunda fase, os outros produtores passam a interferir no texto base.

Comecemos, assim, por descrever e exemplificar as principais operações de textualidade que estão presentes na primeira fase de produção didática. Sabemos que um texto é (micro e macroestruturalmente) coerente se ele contiver, no seu desenvolvimento linear, elementos de recorrência estrita. Esses elementos garantem a unidade temática constitutiva do texto e são expressos por retomadas pronominais, artigos definidos e pronomes demonstrativos, repetições e substituições lexicais, por indicações de recuperação de informações pressupostas ou consideradas inferíveis pelos interlocutores. Essa estratégia de retomada/repetição de elementos e ideias no decorrer do texto é chamada de continuidade (VAL, 1999).

Cavalcante (2014, p. 34) esclarece que as repetições conferem unidade ao texto, já que um dos fatores que fazem com que se perceba o texto como um todo único é a permanência, no desenvolvimento do texto, de elementos constantes. A autora afirma que, para que um texto seja internamente coerente, também é preciso respeitar princípios lógicos elementares, os quais garantam que, no seu desenvolvimento, não se introduza nenhum elemento semântico que contradiga um conteúdo posto ou pressuposto por uma recorrência anterior, ou deduzível desta por inferência. Esse é o princípio de não contradição. Esse princípio não diz respeito somente à lógica interna do texto, uma vez que, externamente, o texto não pode contradizer o mundo a que se refere. Cavalcante esclarece que o mundo representado no texto não precisa ser necessariamente o mundo real, mas explica que "o mundo textual tem que ser compatível com o mundo que o texto representa em um dado gênero” (CAVALCANTE, 2014, p. 36). Entendemos, assim, que a não contradição se aplica também às relações entre texto e contexto, no sentido de que a aceitação de um texto como coerente depende de o interlocutor encontrar compatibilidade entre o mundo textual e seu próprio conhecimento de mundo, seu conjunto de crenças e valores.

Val (1999, p. 25) igualmente elucida que um texto precisa respeitar os elementos lógicos elementares e não contradizer o mundo a que se refere, haja vista que o mundo textual tem que ser compatível com o mundo que o texto representa. Segundo a autora, o princípio de não contradição se aplica não só ao plano conceitual, mas também ao plano da expressão. No contexto da não contradição, Val traz para a discussão o termo "modalidade". Segundo a autora, a modalidade é outro elemento do funcionamento discursivo que faz alusão à atitude do produtor do texto, tanto em relação ao conteúdo proposicional e ao valor de verdade de seu enunciado quanto em relação ao próprio interlocutor. Dessa forma, se levarmos em consideração que o mundo textual pode se expressar linguisticamente por meio do emprego de verbos, expressões e construções textuais, o emprego contraditório desses recursos também pode acarretar dificuldades à interpretação do discurso, uma vez que contraria as expectativas do interlocutor (VAL, 1999).

Podemos dizer que as operações linguísticas têm a ver tanto com as relações cotextuais (relações internas entre texto e texto), quanto com as relações contextuais (relações socioculturais e situacionais específicas) e que essas relações fazem emergir um sujeito histórico e dialogicamente construído (MARCUSCHI, 2008). Com base em Marcuschi, tomamos texto como a unidade máxima de funcionamento da língua, porém não uma unidade do tipo das unidades formais da língua, mas, sim, uma unidade funcional de natureza discursiva, cuja forma é apenas uma realização específica do texto em constituintes linguísticos de natureza morfossintática e lexical. Dessa forma, "o que faz um texto ser texto é a discursividade, inteligibilidade e articulação que ele põe em andamento" (2008, p. 89). Sendo assim, os textos, a partir de uma visão sociointerativa, operam em contextos comunicativos cuja funcionalidade da língua ocorra como uma atividade enunciativa. Para Marcuschi, quando se ensina alguém a lidar com textos, ensina-se mais do que os usos linguísticos; ensinam-se as operações discursivas de produção de sentido dentro de uma determinada cultura, que trazem certos gêneros como formas de ação linguística.

Para Cavalcante, Custódio Filho e Brito (2014), o reconhecimento do estatuto do texto e de sua consequente coerência só é possível se levarmos em consideração o contexto de produção. Os autores explicam 
que o texto é considerado coerente, entre outros motivos, por se adequar à situação de interação prevista no contexto de produção. A partir dessa premissa, entendemos que, no contexto de análise desta pesquisa, as estratégias de textualidade são definidas pelo contexto de produção e não apenas por propriedades imanentes ao texto. Assim, a partir do conhecimento do professor conteudista sobre o gênero que produz e sobre o contexto sociointerativo do qual participa como produtor textual, ele (conteudista) usará estratégias de textualidade em sua composição escrita, a fim de satisfazer um conjunto de condições que promovem a produção de sentidos com o texto.

Sobre essa produção de sentidos, Cavalcante, Cústódio Filho e Brito argumentam que a existência de um texto está sujeita à possibilidade de se atribuir coerência a uma dada ocorrência comunicativa (não exclusivamente linguística). Para os autores, "a coerência surge da percepção de uma unidade negociada de sentido que depende da interação argumentativa do locutor, da coparticipação do interlocutor, das indicações marcadas na superfície do texto e de um vasto conjunto de conhecimentos compartilhados” (p. 21). Por isso, na análise das estratégias de textualidade observadas em uma produção didático-digital-colaborativa, como a que descrevemos neste estudo, levamos em consideração os elementos contextuais e interacionais presentes na avaliação que os sujeitos fazem ao tentarem perceber unidade de sentido. Essas estratégias de textualização são feitas na fase de produção individual e avaliadas na fase de produção mediada pelos sujeitos que escrevem de forma colaborativa o gênero webaula. Na seção seguinte, reproduzimos, em forma de imagem, a primeira página do texto-base (primeira versão da webaula) escrito pelo professor conteudista do curso de Educação Profissional, Científica e Tecnológica do IFCE.

\section{Avaliação das Seções Temáticas do Material Didático: foco na interlocução E NA FOCALIZAÇÃo}

$\mathrm{Na}$ análise do material didático, vimos que existe uma sequência textual característica tanto no texto impresso do material didático como no texto da webaula. Tal sequência é construída como um texto composto por seções didáticas, comuns nos livros didáticos, por exemplo. Nessa sequência, o professor desenvolve seções típicas na escrita didática de material didático para e EaD, como: a) título da aula; b) apresentação da aula; c) objetivos gerais da aula; d) título do tópico; e) objetivos específicos do tópico; f) introdução do tópico; e g) conteúdo informacional da aula propriamente dito. Essas seções seriam o que Koch (2004, p. 44) chama de fatores de contextualização prospectivos, pois elas permitem avançar as expectativas do leitor sobre o texto, situando-o em um universo contextual de interação. Embora esses elementos pareçam não ser necessários para a constituição da textualidade, eles contribuem para a contextualização (MARCUSCHI, 2012, p. 39) e são muitas vezes decisivos para indicar a progressão do texto e para proporcionar a compreensão do gênero webaula pelo leitor.

Essa forma de separação em seções é feita a fim de proporcionar aos leitores do gênero webaula (alunos que estudam na modalidade a distância) condições de acesso à compreensão do texto, para que ele seja interpretado sem maiores problemas. Por outro lado, não é, porém, o fato de o texto estar dividido em seções temáticas que por si só garantirá sua inteligibilidade, mas, sim, o atendimento conjunto de condições sociais de uso e o uso, discursivamente orientado, das operações de textualidade presentes no texto que darão base para a compreensão.

Nas figuras que apresentamos a seguir, vemos as duas primeiras páginas do conteúdo bruto de uma webaula do curso de EPCT produzida pelo professor da disciplina Informática Educativa. A amostra se refere à terceira aula dessa disciplina. Cada uma das seções requer estratégias de textualização que se referem mais especificamente aos aspectos linguísticos (o ato de escrita verbalmente produzido). 


\section{INFORMÁTICA EDUCATIVA}

\section{LICENCIATURA EM EPCT}

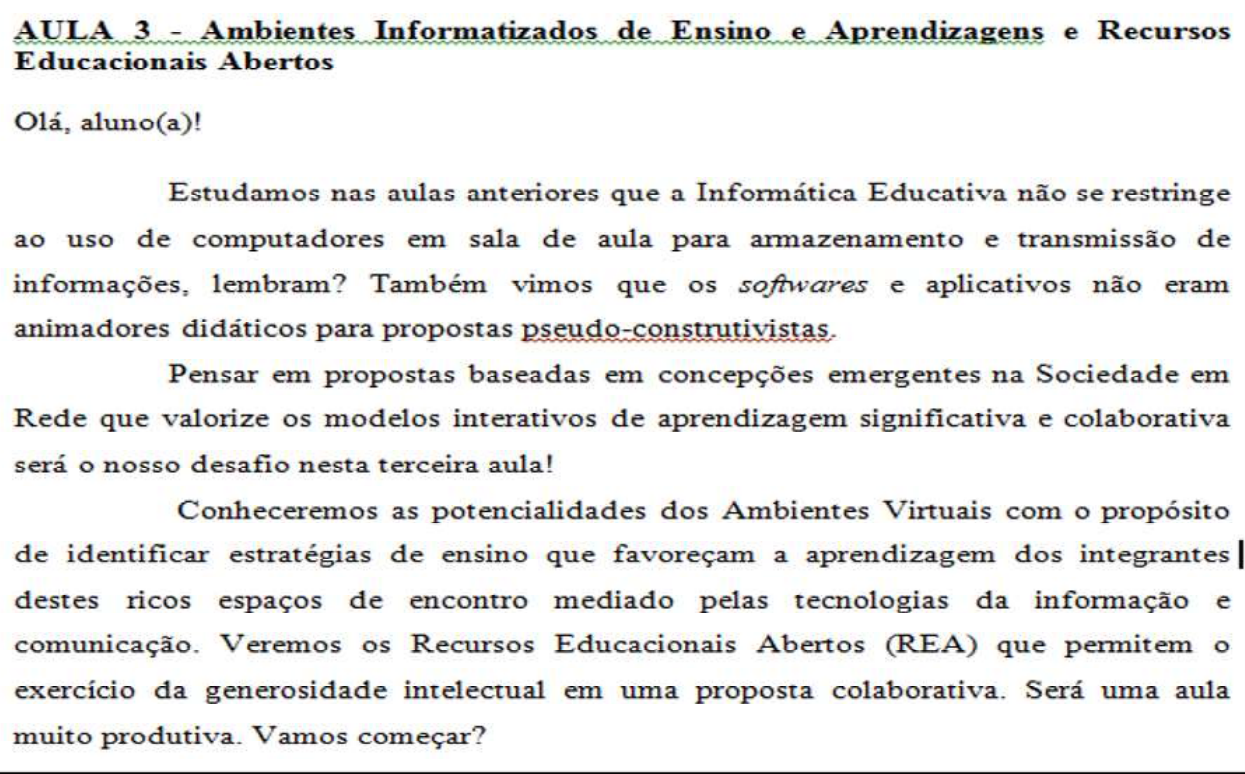

Fonte: IFCE.

Figura 1 - Aula 3 da disciplina Informática Educativa: título e apresentação da aula

Sabemos que o primeiro elemento que desencadeia expectativas sobre um texto é o título. Ele serve como fio condutor para as inferências feitas pelos interlocutores (KOCH; ELIAS, 2009), como ativador de conhecimentos prévios necessários para a compreensão, pois permite fazer previsões, levantar hipóteses, que serão testadas pelos interlocutores ao longo de sua interação com o texto.

$\mathrm{Na}$ Figura 1, podemos observar que o conteudista faz uma interlocução direta como os alunos na seção de apresentação da aula, pelo uso do vocativo (Olá, aluno(a)!; dos verbos na primeira pessoa do plural [estudaremos, conbeceremos] e de frases retóricas com interrogativas diretas [perguntas diretas aos alunos, que tentam simular uma interação face a face). Nessa interlocução, ele retoma o que foi visto nas aulas anteriores e explica o que será estudado na aula. Esse tipo de escrita é socialmente reconhecido e aceito como escrita didática comum em gêneros didáticos escolares e acadêmicos. Por isso, essas estratégias de interlocução são esperadas e fazem parte da tentativa de manter o tom dialogal necessário a um material didático para a EaD. A seguir, apresentamos a continuação da aula.

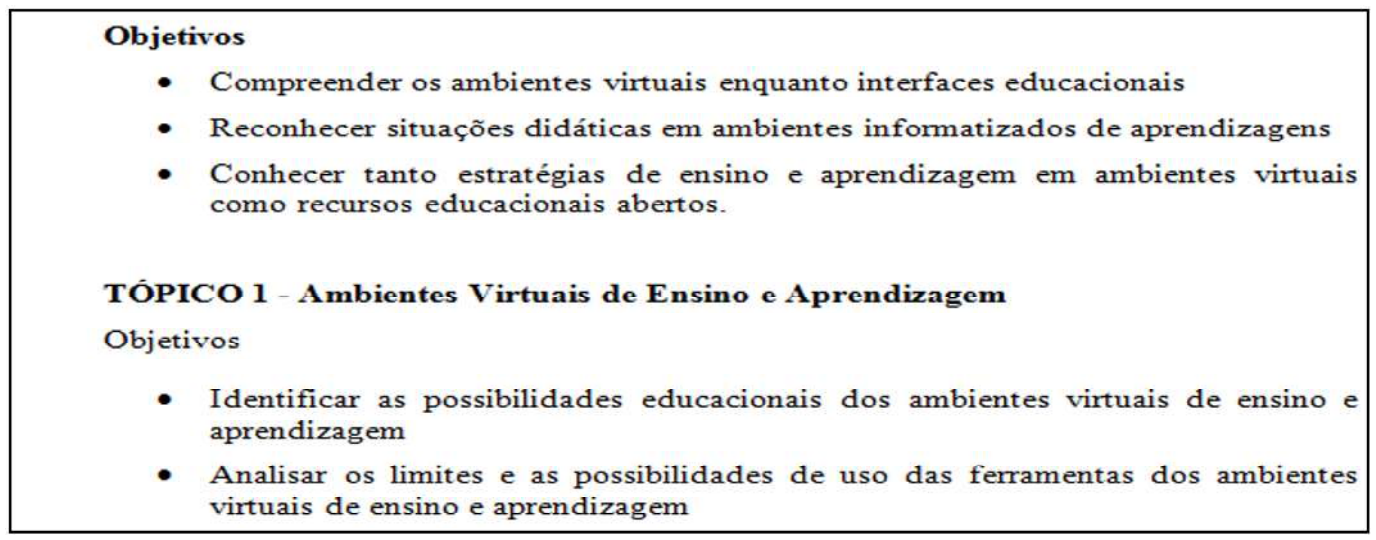

Fonte: IFCE.

Figura 2 - Aula 3 de Informática Educativa: objetivos gerais e objetivos específicos do tópico 1 
Depois da apresentação da aula, são colocados os objetivos gerais da aula, o título do tópico 1 e os objetivos específicos do tópico. Neles a figura do aluno é reconhecida como o foco dos objetivos, isto é, como aquele que deverá alcançar tais metas ao final da leitura da webaula. Os objetivos atuam como um critério de focalização $(\mathrm{KOCH}, 2004)$ e resumem as ações de aprendizagem que devem ocorrer pelo aluno. Em seguida, inicia-se a introdução do conteúdo informacional (argumentação e exposição do tópico de aula), que orienta o aluno sobre as ideias que serão discutidas no tópico em questão. Vejamos, a seguir, um exemplo de introdução do tópico 1 da aula 3 da disciplina Informática Educativa. Nela, o conteudista pauta sua argumentação no atual cenário de formação, mediado pelas tecnologias midiáticas.

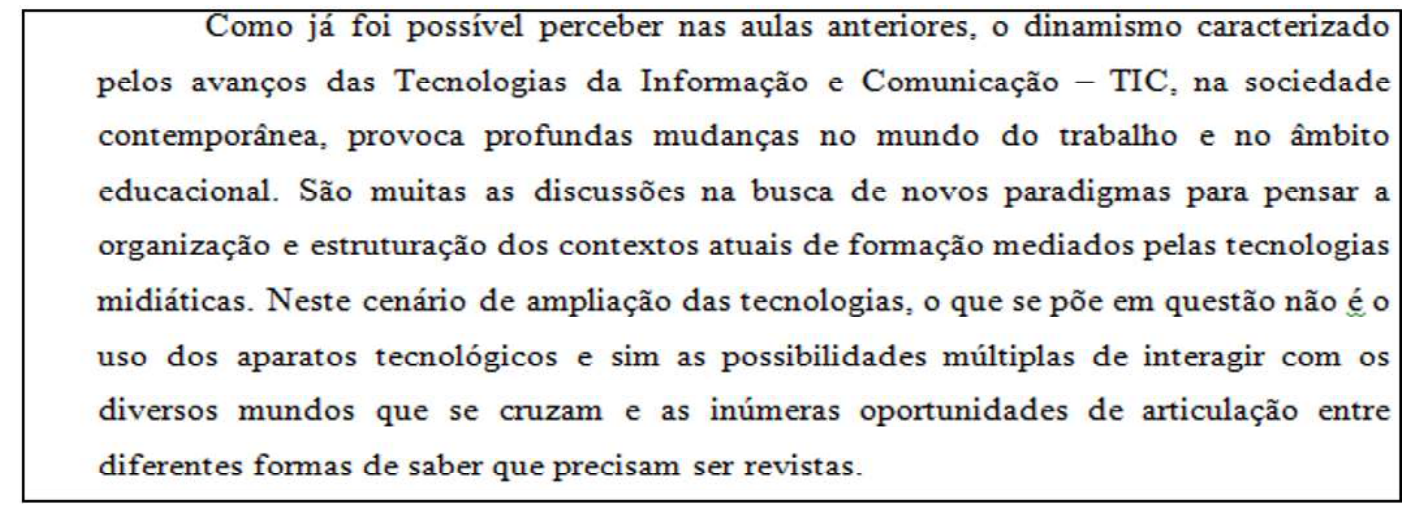

Fonte: IFCE.

Figura 3 - Aula 3 da disciplina Informática Educativa: introdução do tópico 1

Como podemos observar, existem, nessas sequências textuais, estratégias de textualização desenvolvidas pelo professor conteudista na fase de produção didática individual, que tentam estabelecer e manter a continuidade, a articulação, a progressão temática e a informatividade entre o conjunto dos enunciados e o tópico discursivo. Para que isso ocorra, é preciso levar em consideração não apenas a estrutura básica da tipologia argumentativo-expositiva de introdução à desenvolvimento à conclusão presente nos gêneros acadêmicos, mas também as seções didáticas previamente estabelecidas que marcam os gêneros didáticos como a webaula (além dos recursos multissemióticos), de modo que os enunciados sejam interpretáveis como uma unidade temática.

$\mathrm{Na}$ Figura 4, na página seguinte, temos um exemplo do desenvolvimento da aula 3 da disciplina Informática Educativa, em que o conteudista textualiza o conteúdo didático por meio de elementos que garantam a unidade de sentido e que deixem claro o propósito comunicativo do texto.

Quando analisamos o conteúdo presente na Figura 4, vemos que as estratégias de interlocução direta percebidas na apresentação e na introdução do tópico dão lugar a uma estrutura tradicional de argumentação presente nos gêneros acadêmicos. Essa estrutura é marcada pela apresentação do tema discutido a partir de uma opinião geral e da exposição dos fatos e acontecimentos para o interlocutor. Essa apresentação constitui a base para a progressão e a continuidade dos argumentos que serão articulados no desenvolvimento, a fim de se chegar à síntese da aula na última seção temática dedicada ao fechamento do tópico.

$\mathrm{Na}$ webaula, também há ícones, links, áudios e vídeos que são postados no ambiente virtual de aprendizagem na última etapa da produção colaborativa (fase didática hipertextual). Na Figura 5, é possível perceber a indicação que o professor conteudista faz em seu texto de um ícone chamado "Guarde bem isso". O conteúdo informacional desse ícone obviamente deverá seguir os mesmos critérios de textualidade, ainda que, ao ser postado no AVA, ele passe por uma transformação do material escrito (material impresso) em webaula (material hipertextual) na última fase de produção. 
Repensar a educação nesse contexto ultrapassa a perspectiva tecnicista de aprender a lidar com as tecnologias, armazenando, transmitindo e estocando informações em uma via única de comunicação. O grande desafio da educação centra-se exatamente na produção de conhecimento em rede, em que todos os sujeitos conectados são responsáveis e participantes coletivos da construção de saberes significativos e contextualizados. Nessa formação, incentiva-se o pensar crítico e criativo pautado em noções de ética, solidariedade e colaboração.

As técnicas de comunicação e o papel da informática com base digital não seria o de criar as máquinas de ensinar ou, ainda, de substituir o homem, promovendo uma pseude "inteligência artificial, mas promover a construção de coletivos inteligentes, nos quais as potencialidades sociais e cognitivas de cada um poderão desenvolver-se e ampliar-se de maneira recíproca" LLÈVY, 2000, p. 25).

Fonte: IFCE.

Figura 4 - Aula 3 de Informática Educativa: conteúdo informacional

A realidade das interações e do convívio das pessoas em redes online estabelece novos espaços de convivência, construção coletiva, debates sociais e de aprendizagem que fazem emergir os Ambientes Virtuais. Esses espaços de sociabilidade na rede de computadores se efetivam pelo encontro de sujeitos dispostos a compartilhar informações e saberes, através da atual infraestrutura da internet que desterritorializa e liberta a comunicação dos limites impostos pelas noções de tempo e espaço, podendo implementar uma comunicação dinâmica com grande potencial para a interatividade.

ÍCONE GUARDE BEM ISSO
As redes sociais (facebook,
youtube, twitter, whatsAps, flickr...)
são ambientes de trânsito e fluxo de
pessoas e informações podendo se
constituir em ambientes virtuais de
aprendizagens, no entanto para se
caracterizarem como ambientes
virtuais de ensino necessitam de uma
intencionalidade educativa explícita
e compartilhada.

Fonte: IFCE.

Figura 5 - Aula 3 de Informática Educativa: conteúdo com indicação de ícone

Nas figuras analisadas, vimos, então, que existem seções que atuam como fatores de contextualização prospectivos e fatores de contextualização que salientam o tópico discursivo, como os ícones, os quais favorecem a continuidade temática e a progressão textual. Para Koch e Elias (2009), o suporte textual também atua como fator de contextualização, pois ajuda a ancorar o texto numa situação comunicativa e auxilia no estabelecimento da coerência. No caso da webaula, então, tanto as seções didáticas, os recursos multissemióticos, como o suporte (o ambiente virtual de aprendizagem) se destacam como contextualizadores que oferecem importantes pistas aos alunos para a construção dos sentidos do texto.

Nas Figuras 4 e 5, que ilustram o conteúdo informacional do tópico 1, da aula 3 de Informática Educativa, vemos que há uma tentativa de manutenção do tópico discursivo (tema central de um texto) que gira em torno da discussão sobre os Ambientes Virtuais de Aprendizagem. Cavalcante, Custódio Filho e Brito (2014, p. 25) explicam que uma das formas de estabelecer ligação entre as partes do texto transcorre pela retomada de elementos textuais por meio de expressões nominais (expressões referenciais). Esse conjunto de expressões nominais contribui para estabelecer os referentes do texto. 
Dessa forma, entendemos, segundo Cavalcante, Custódio Filho e Brito, que retomadas de um mesmo referente - como neste cenário, nesse contexto, esses espaços -, marcam o percurso de uma cadeia correferencial. Esse percurso é construído pelo conteudista para indicar uma cadeia em torno de um referente $-<$ novos espaços de convivência $>$. Assim, é comum que o desenvolvimento dos referentes no texto demande o acionamento de novas expressões lexicais. Essas expressões podem vir acompanhadas do artigo definido (o uso dos aparatos tecnológicos, a perspectiva tecnicista, o grande desafio da educação); podem vir como repetições lexicais no texto (educação, comunicação, espaços, tecnologias); ou como substituições lexicais (novos paradigmas à diferentes formas de saber, o mundo do trabalho à diversos mundos que se cruzam, tecnologias midiáticas à aparatos tecnológicos, produção de conhecimentos em rede à participantes coletivos da construção de saberes significativos etc.). Esse modo de estabelecer e manter a informação temática no texto da webaula procura garantir a manutenção da continuidade textual. Os exemplos dados mostram, assim, como o professor conteudista procura atender ao princípio de continuidade temática.

\section{Avaliação das Seções Temáticas do Material Didático: foco nas metarregras}

Como vimos na seção anterior, no que se refere ao estabelecimento da coerência textual, Cavalcante (2014) explica que uma boa ferramenta para avaliarmos as quebras localizadas de coerência do texto são as metarregras formuladas por Charolles (1978) e difundidas, no Brasil, por Val (1999). Cavalcante destaca as metarregras da continuidade, da progressão, da não contradição e da articulação. ${ }^{5}$

Assim, no que se refere ao elemento "modalidade" no estudo do critério da não contradição, podemos avaliar essa estratégia discursiva quando o professor conteudista faz uma estreita relação entre os objetivos gerais da aula, os objetivos específicos do tópico e o que ele desenvolveu no conteúdo informacional do texto. Isso quer dizer que o conteúdo proposicional indicado pelos objetivos gera um valor de verdade que será (ou não) confirmado não só pelos alunos (interlocutores finais do gênero webaula), mas também pelos outros sujeitos que participam do processo de escrita colaborativa. Caso contrário, isto é, caso não se confirmem as expectativas do interlocutor na construção da argumentação do texto pretendida nos objetivos, a estratégia da não contradição terá sido desrespeitada pelo produtor do texto na primeira fase da escrita colaborativa.

Vamos representar a Figura 6 a fim de analisarmos o critério da não contradição. Nosso foco é perceber a contradição (uma vez que o princípio da não contradição deve ser norteador para a textualidade) que existe entre o que foi planejado como objetivos gerais e específicos tanto da aula 3 quanto do tópico 1 pelo professor conteudista e a possibilidade de realização desses objetivos ao final da leitura da webaula pelos alunos que estudam na modalidade a distância.

Temos, na Figura 6, na página seguinte, que os objetivos desenvolvidos na webaula criam um horizonte de compatibilidade entre o que está proposto e o que se efetiva no texto. A manifestação desse horizonte de compatibilidade entre o que está proposto como objetivo e o que é realizado textualmente para atingir esses objetivos ocorre também por meio dos verbos escolhidos para cada um dos objetivos (compreender, reconhecer, conhecer - objetivos gerais da aula 3; identificar e analisar - objetivos específicos do tópico 1), os quais criam, nos sujeitos que participam da webaula, uma expectativa que tem estreita relação com o princípio da não contradição. Dessa maneira, ao final da leitura da webaula sobre Ambientes Informatizados de Ensino e

\footnotetext{
${ }^{5}$ Val (1999) fez uma adaptação das metarregras de Charolles (1978). Nesta pesquisa tomamos como referência Val (1999) e Cavalcante (2014), que segue a adaptação de Val, e não o texto original de Charolles (1978).
} 
Aprendizagens e Recursos Educacionais Abertos, tanto os interlocutores que produzem colaborativamente a webaula (DE, revisor, conteudista ${ }^{6}$ ) como os interlocutores previstos que acessam a webaula (os alunos do curso de EPCT) tomam os objetivos propostos na webaula como norte e esperam que eles sejam cumpridos, levando-se em consideração também as demais estratégias de textualidade.

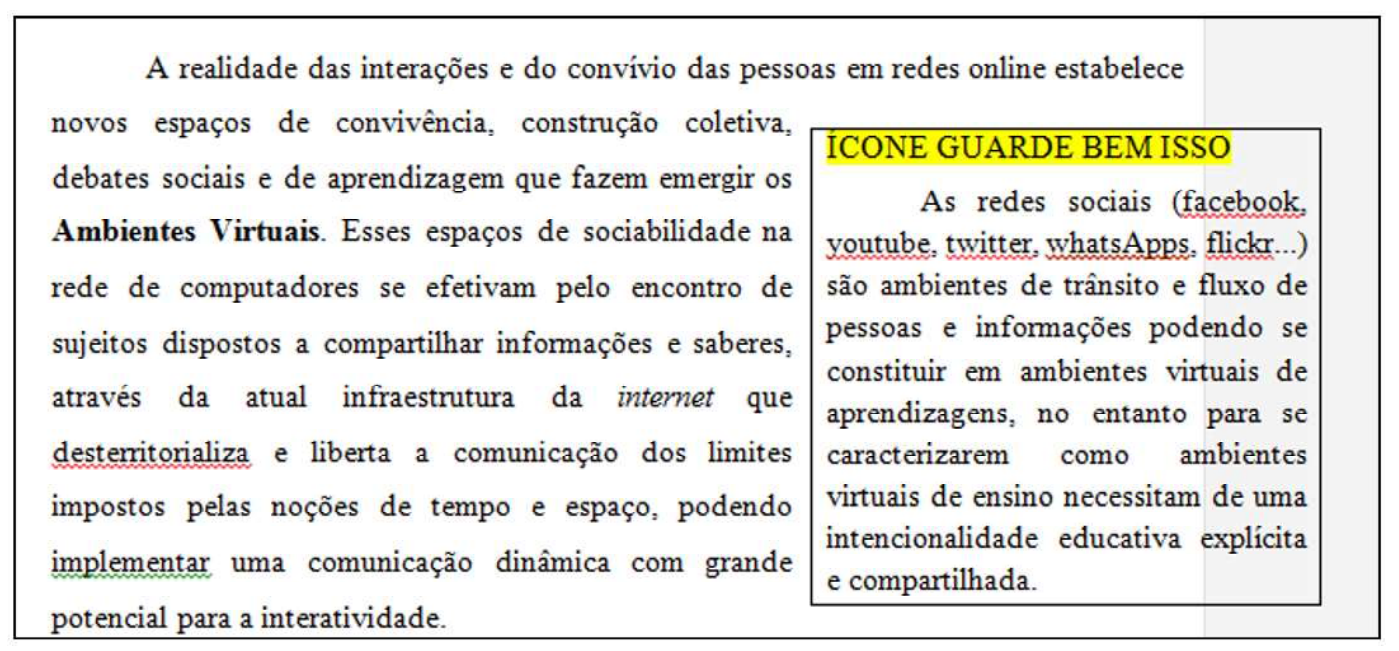

Fonte: IFCE.

Figura 6 - Aula 3 de Informática Educativa: análise da não contradição

Tomemos como exemplo o segundo objetivo específico do tópico 1, analisar os limites e as possibilidades de uso das ferramentas dos ambientes virtuais de ensino e aprendizagem. Segundo o horizonte de compatibilidade estabelecido pelo que se espera do gênero, a expectativa gerada pelo objetivo é a de que, ao final do tópico 1 da aula 3 (que somam sete páginas escritas pelo professor conteudista), os limites e as possibilidades de uso das ferramentas dos ambientes virtuais de ensino e aprendizagem serão analisados. Nesse contexto de enunciação, é verdadeiramente possível que os alunos analisem os limites e as possibilidades dos usos das ferramentas de ambientes virtuais em um texto didático como a webaula apenas pelo conteúdo discursivo da webaula? Dito de outra forma: é possível analisar limites e possibilidade sem uma pesquisa ampla que envolva uma metodologia que dê conta de objetivos como este? Acreditamos que não.

Essas reflexões nos ajudam a perceber como os objetivos assumem um valor de verdade no enunciado proposto pelo conteudista e como a relação entre o(s) interlocutor(es) se estabelecem em relação ao conteúdo proposicional. Estamos, dessa forma, levando em consideração o funcionamento discurso e fazendo uma estreita relação com o princípio da não contradição. Como se trata ainda da primeira versão do texto bruto produzido na fase didática individual, talvez essa contradição seja indicada ou corrigida pelos outros sujeitos que participam da produção colaborativa (DE e revisor). Sabemos, então, que os fatos que denotam o mundo representado textualmente devem estar diretamente relacionados, encadeados, articulados. Essa relação como os argumentos são apresentados no texto - e a forma como eles se encadeiam uns com os outros - é característica da metarregra da articulação.

Val (1999, p. 27) explica que a articulação tem a ver com a maneira como os fatos e os conceitos apresentados se encadeiam no texto, como se organizam, como exercem relações uns com os outros e como

\footnotetext{
${ }^{6}$ O professor conteudista faz, no procedimento da reversibilidade, uma avaliação sobre o conteúdo bruto que ele escreveu. Ele observa as inferências feitas em seu texto e toma uma atitude responsiva sobre a entoação avaliativa feita pelos outros sujeitos. Essa atitude responsiva pode ser: alterar o texto conforme as indicações avaliativas; aceitar as alterações feitas em seu texto; ou manter o texto original produzido na fase individual.
} 
essas relações podem ser avaliadas. Para Val, avaliar a articulação compreende verificar se as ideias desenvolvidas no plano discursivo do texto têm a ver com as outras ideias nele apresentadas e analisar que tipo específico de relação tais ideias estabelecem. Se focalizarmos o plano microestrutural, veremos que a articulação se realiza em termos de uso de conectivos e articuladores, que sinalizam as relações semânticas entre as orações e partes do texto e indicam ao interlocutor a ordenação e a organização concebidas pelo locutor.

Sobre os articuladores textuais na argumentação, Koch e Elias (2016, p. 121) explicam que as marcas responsáveis pelo encadeamento de segmentos textuais (orações, períodos, parágrafos, sequências maiores) de qualquer extensão são denominadas articuladores textuais, operadores de discurso ou marcadores discursivos. Esses articuladores atuam em três diferentes níveis e têm um importante papel para o estabelecimento da coesão, da coerência e da organização argumentativa no texto. Os três níveis de articuladores são: o nível da organização global do texto (articulações entre as sequências ou partes maiores do texto); o nível intermediário (encadeamento entre parágrafos e períodos); e o nível microestrutural (encadeamento entre orações e termos da oração).

Ainda segundo Koch e Elias (2016), os articuladores textuais podem assumir variadas funções no texto. No caso dos textos didático-digitais produzidos para alunos que estudam na EaD, bem como em outros textos argumentativos, a estratégia da articulação feita pelo professor conteudista seria pautada no estabelecimento da relação entre dois enunciados distintos, em que o segundo é encadeado com o primeiro, que foi tomado como tema. Teríamos, nesse caso, como foco de análise dos operadores discursivos usados no texto não apenas as relações lógico-semânticas que ocorrem entre o conteúdo de duas orações, mas também os articuladores discursivo-argumentativos que determinam justamente a relação entre enunciados diferentes.

Esses articuladores, ainda conforme Koch e Elias (2016), determinam a orientação argumentativa do enunciado que introduzem e estabelecem como relações a conjunção (operadores que ligam argumentos que apontam para a mesma conclusão); a disjunção (operadores que ligam argumentos que levam o interlocutor ou a aceitar a opinião presente no primeiro argumento ou a refutá-la); a contrajunção (operadores que ligam argumentos que apontam para orientações argumentativas diferentes, devendo prevalecer a orientação do enunciado introduzido pelo articulador - como o "mas", por exemplo); a explicaşão (operadores que iniciam um argumento para a tese/opinião expressa no enunciado anterior); a comprovação (operadores que ligam argumentos que apresentam provas de que o que foi expresso no enunciado relacionado é verdadeiro); a conclusão (operadores que introduzem um enunciado de valor conclusivo em relação ao enunciado anterior); comparação (operadores que estabelecem relação entre um termo comparante e um termo comparado de igualdade, superioridade e inferioridade); a generalização (operadores que estabelecem relação em que o segundo enunciado exprime uma generalização do fato contido no primeiro); a especificação (operadores que estabelecem relação em que o segundo enunciado particulariza uma declaração mais geral apresentada no primeiro); e a correção (operadores que estabelecem relação em que o segundo enunciado corrige ou redefine o conteúdo do primeiro).

Outro tipo de articuladores muito presentes no texto da webaula são os articuladores de organização textual e os metadiscursivos. Os articuladores de organização textual orientam a interpretação do texto e organização espacial, sinalizando a abertura, a intermediação e o fechamento da composição escrita no gênero. Como exemplos desses articuladores organizacionais, temos as seguintes passagens escritas pelo conteudista no texto-base da aula 3 de Informática Educativa:

a) Neste momento dos nossos estudos e investigações, já compreendemos que a Web possibilita a disponibilização de plataformas globais para acesso e criação de grande quantidade e variedade de conteúdos na perspectiva todos-todos [...].

b) Estudamos nas aulas anteriores que a Informática Educativa não se restringe ao uso de computadores em sala de aula para armazenamento e transmissão de informações, lembram? 
c) Vamos, agora, investigar, pesquisar e descobrir repositórios e sites que disponibilizam REA com possibilidades de trocas permanentes, remixagens, recriações criativas e éticas na socialização do conhecimento.

d) Tivemos, nos últimos anos, a inserção dos computadores nas salas de aula e a desmistificação das máquinas de ensinar de Skinner [...].

e) Atualmente temos os REAs que avançam na proposta dos objetos de aprendizagens pelas possibilidades de compartilhamento e adaptação, promovendo uma reconfiguração em termos de autoria $[. .$.$] .$

Já os articuladores metadiscursivos introduzem comentários ora sobre o modo como o enunciado foi formulado, ora sobre a própria enunciação. Koch e Elias (2016) explicam que, de acordo com a função que esses articuladores assumem, eles podem ser modalizadores (realmente, logicamente, obviamente etc.); delimitadores de domínio (pedagogicamente, linguisticamente, sociologicamente etc.), voltados para a formulação textual ${ }^{7}$ (em resumo, em primeiro lugar, além disso etc.); e evidenciadores da propriedade autorreflexiva da linguagem (quer dizer, em outras palavras, digamos assim etc.).

Esse estudo do princípio da articulação e dos articuladores usados na argumentação, como estratégia discursiva empreendida pelo professor conteudista na primeira fase da produção do texto da webaula, é interessante para observamos como o produtor textual encadeia seus enunciados para a construção dos sentidos em um texto didático-acadêmico. Por meio da análise dos articuladores, podemos ter uma noção de como o caráter dialogal e estilístico é desenvolvido no texto. A essa análise se relaciona muito bem a metarregra da progressão, como uma tentativa de manter a unidade temática e oferecer a ela uma contribuição semântica constantemente renovada.

Já sabemos que o texto precisa manter a unidade temática e que precisa se desenvolver, a fim de mostrar que tem algo a dizer. A progressão de um texto é justamente a apresentação de novos temas ou subtemas relacionados ao tema central, trazendo novos comentários sobre os temas já introduzidos. Segundo Cavalcante (2014, p. 34), é preciso, além da retomada de conceitos, que o texto apresente informações novas a respeito dos elementos retomados para que o sentido do texto progrida. Para a autora, a progressão é obtida a partir da adesão de novos conceitos e informações aos elementos responsáveis pela continuidade.

Koch e Elias (2016) explicam que, quando lemos um texto argumentativo,

acompanhamos o raciocínio do autor, identificamos os seus argumentos, ativamos vários conhecimentos, preenchemos lacunas, e construímos sentido. E tudo acontece porque o autor, pensando no objetivo e no leitor de seu texto, elege um tema ou assunto e o desenvolve, observando um equilíbrio variável entre duas exigências fundamentais: repetição (retroação) e progressão. Ou seja, o autor remete a algo que já está presente na memória do leitor e, considerando essa base, vai acrescentando informações novas, que, por sua vez, passarão a constituir suportes para informações subsequentes (p. 85).

Essa ativação de conhecimentos para a construção de sentidos e o acréscimo de informações novas dizem respeito a qualquer texto como construto sociocultural. Porém, antes de seguirmos em frente na discussão sobre a avaliação de material para a $\mathrm{EaD}$ de forma colaborativa, é importante, mais uma vez, ressaltar outra diferença em relação à escrita de material didático-acadêmico produzido para a EaD e à escrita de um livro didático. Esta diferença se dá em função do gênero (e do suporte) que os sujeitos estão produzindo: uma webaula que será publicada no Ambiente Virtual de Aprendizagem (AVA). Isso significa que a versão do

\footnotetext{
${ }^{7}$ Os articuladores voltados para a formulação textual, segundo Koch e Elias (2016, p. 148), exercem três funções: a) indicar o estatuto de um segmento textual em relação aos anteriores, como ocorre quando usamos marcadores; b). introduzir tópico; e c) interromper ou reintroduzir o tópico.
} 
material impresso produzido, ao final do processo de avaliação da textualidade pelos sujeitos, ganha interatividade, cores, imagens, animações, vídeos, links e ícones específicos, a fim de adquirir um formato próprio para o ambiente virtual e ser, então, postada no Moodle. ${ }^{8}$ Nesse AVA, alunos e professores interagem por meio de textos que pertencem a gêneros textuais como fóruns de discussão, wikis, chats, quizzes etc. Todos esses gêneros fazem parte do AVA, inclusive o gênero webaula. Na próxima seção, vamos analisar os diálogos avaliativos feitos pelos sujeitos da equipe multidisciplinar nas versões textos da webaula.

\section{Avaliação do Material Didático: foco na informatividade}

Após discorrer sobre as metarregras de coerência, neste tópico destacamos a informatividade como fator de textualidade constitutivo do texto didático-acadêmico. Isso porque muitas das interlocuções avaliativas feitas pelos membros da equipe multidisciplinar no IFCE são pautadas nesse fator de textualidade. A informatividade diz respeito ao grau de previsibilidade da informação veiculada pelo texto. Um texto será menos informativo quanto mais previsível for a informação por ele trazida. Val (1999) afirma que o interesse do interlocutor pelo texto vai depender do grau de informatividade presente na composição textual. Assim, em função da progressão e da informatividade, o produtor seleciona as palavras e distribui a informação no texto, cabendo ao interlocutor calcular o sentido da informação com maior ou menor facilidade. O sujeito que escreve o texto didático-acadêmico, portanto, organiza a progressão temática em função da suficiência de dados previstos para o tema.

Sobre a suficiência de dados, Antunes (2010, p. 74) destaca a relevância informativa e sua relação com o maior e o menor grau de novidade, seja ela expressa pela forma ou pelo conteúdo. Para a autora, quanto mais o texto apresenta novidades, quanto mais foge de obviedades, mais ele é relevante. Antunes, porém, ressalta que o grau de novidade requisitado para o texto é determinado por razões contextuais e que, em cada situação sociodiscursiva, a relevância informativa é avaliada. No texto da webaula, por exemplo, os sujeitos que escrevem o texto didático-digital comumente buscam simular diálogos com os interlocutores quando pretendem anunciar novidades conceituais, ou seja, quando pretendem trazer ao texto novas informações. Eles fazem uma espécie de interlocução direta com o leitor (aluno), na qual destacam a progressão temática e a relevância informática do conteúdo. Na Figura 7, na página seguinte, vemos que há uma ruptura no fluxo do discurso indireto do texto para que seja colocada uma pergunta direta (discurso direto) ao aluno, a fim de simular um diálogo e provocar o aluno sobre novas informações sobre o tema.

Por esse exemplo, vemos que, além dos elementos já vistos até aqui - e que constroem a tessitura , há, ainda, nesse jogo enunciativo de produção do texto da webaula, uma estratégia de interlocução utilizada pelo produtor do texto, que acreditamos ser digna de nota. Ela vem ao encontro das demais operações de textualização utilizadas pelo professor conteudista nessa fase de produção didática individual e estabelece um diálogo marcado no texto com os alunos que o lerão. Trata-se da beterogeneidade enunciativa, definida por AuthierRevuz (1990) quando se analisam os processos enunciativos a partir da perspectiva bakhtiniana da presença do outro na enunciação.

Authier-Revuz (1990, p. 26) faz estreita relação entre o conceito de heterogeneidade enunciativa e o conceito de dialogismo empreendido por Bakhtin. Segundo ela, o dialogismo do círculo de Bakhtin não tem como preocupação central o diálogo face a face, mas constitui, por meio de uma reflexão multiforme, semiótica e literária, uma teoria da dialogização interna do discurso. Isso porque as palavras são, em parte, sempre e inevitavelmente, as palavras dos outros. A problemática da heterogeneidade, então, é formulada a partir da

${ }^{8}$ Moodle é o ambiente virtual de aprendizagem usado pelo IFCE para postar as webaulas dos cursos na modalidade a distância. 
noção de heterogeneidades enunciativas, apresentadas como sendo de dois tipos: a constitutiva e a mostrada, consideradas como processos distintos.

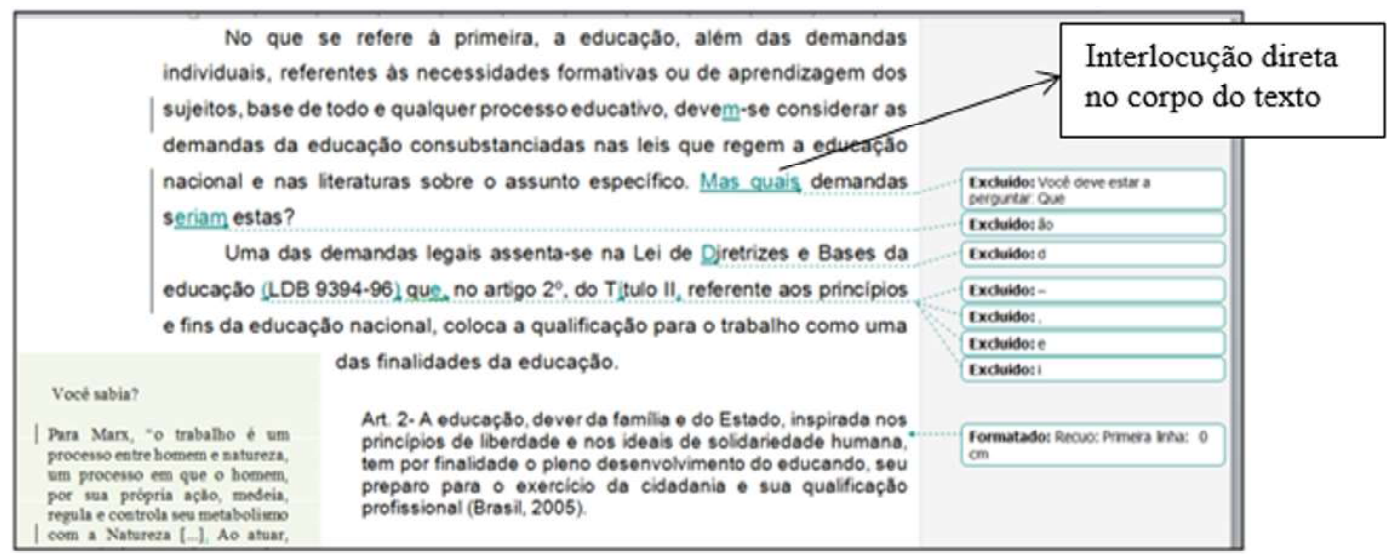

Fonte: IFCE.

Figura 7 - Aula 3 de Projetos Políticos Pedagógicos: relevância informativa e interlocução direta

A heterogeneidade constitutiva refere-se aos processos reais de constituição de um discurso e se assemelha ao dialogismo bakhtiniano constituído no debate com a alteridade. Authier-Revuz explica que esse conceito tem como base a ideia de que nenhuma palavra é neutra, já que todo discurso é carregado pelos discursos nos quais viveu sua existência socialmente sustentada. Os discursos alheios seriam um centro exterior constitutivo com o qual se tece a trama do próprio discurso. Daí a ideia de heterogeneidade constitutiva.

Nessa análise das estratégias enunciativas, nos chamou atenção o conceito de heterogeneidade mostrada como um recurso de textualização e de estilo utilizado pelos produtores do texto da webaula. Ela diz respeito aos processos de representação de um discurso em outro discurso localizável e identificável. Essa heterogeneidade pode aparecer na forma marcada (discurso direto, por exemplo) ou não marcada (paráfrase, por exemplo). Authier-Revuz (1990) explica que a heterogeneidade mostrada se constitui como um fragmento no texto, entre os elementos linguísticos de que faz uso o interlocutor, que acompanha uma ruptura sintática. Por exemplo, quando o conteudista introduz uma marcação mostrada de um discurso direto em forma de uma pergunta retórica dialogada - como em

a) Estudamos nas aulas anteriores que a Informática Educativa não se restringe ao uso de computadores em sala de aula para armazenamento e transmissão de informações, lembram?

b) Veremos os Recursos Educacionais Abertos (REA) que permitem o exercício da generosidade intelectual em uma proposta colaborativa. Será uma aula muito produtiva. Vamos começar?

- temos um discurso direto introduzido por um verbo, ou uma expressão verbal, nitidamente delimitado na cadeia discursiva argumentativa, que remete para outro lugar: aquele de um outro ato de enunciação (p. 29). Assim, essa estratégia utilizada pelo produtor para marcar a presença do interlocutor em seu texto ganha o lugar de um fragmento de estatuto diferente na linearidade da cadeia textual e marca a alteridade explicitamente especificada a que o fragmento remete.

Essa heterogeneidade mostrada pode também ser admitida como um articulador que determina a orientação argumentativa do enunciado que estabelecem a relação de conjunção, por exemplo. Assim, nessa perspectiva de encadeamento, ela atua também com elemento de progressão marcada e auxilia na construção da informatividade quando relaciona um dado já conhecido pelos interlocutores a um dado que será tema da webaula em questão. 
Com a descrição e a exemplificação da heterogeneidade mostrada, fechamos este subtópico sobre as estratégias de textualização utilizadas pelos professores conteudistas na fase de produção didática individual. Vimos, nesta seção, que os fatores de contextualização prospectivos e de focalização permitem avançar expectativas sobre o texto - como o título da aula, a apresentação da aula, os objetivos, a introdução do tópico e o conteúdo informacional -, bem como as metarregras de coerência: a continuidade, a articulação, a progressão temática e o fator de textualidade informatividade. Também discutimos neste subtópico a ideia de heterogeneidade enunciativa, com ênfase na heterogeneidade mostrada como recurso de interlocução que está em sintonia com as outras formas de textualidade.

A seguir, apresentamos o Quadro 1, que resume as principais operações de validação textualidade no material didático-acadêmico produzido pelo IFCE, que foram descritas e analisadas neste artigo. Elas nos dão uma dimensão dos aspectos que são levados em consideração na escrita do texto-base da webaula e, também, dos aspectos que são avaliados nas etapas de escrita colaborativa de uma webaula.

Quadro 1 - Operações de textualidade, descrição e implicações discursivas

\begin{tabular}{|c|c|c|}
\hline Operações de textualização & Descrição & Implicação discursiva \\
\hline Focalização & $\begin{array}{l}\text { Diz respeito aos objetivos gerais da aula, } \\
\text { títulos dos tópicos e objetivos específicos } \\
\text { do tópico, ícones, AVA. }\end{array}$ & Fatores de contextualização \\
\hline Continuidade & $\begin{array}{l}\text { Diz respeito às retomadas de elementos e } \\
\text { ideias no decorrer do texto, bem como à } \\
\text { construção dos referentes no texto. }\end{array}$ & Manutenção do tópico discursivo \\
\hline Não contradição & $\begin{array}{l}\text { Diz respeito à lógica interna do texto. } \\
\text { Aplica-se também às relações entre texto e } \\
\text { contexto. }\end{array}$ & $\begin{array}{l}\text { Expectativas geradas pelos objetivos do } \\
\text { texto }\end{array}$ \\
\hline Articulação & $\begin{array}{l}\text { Diz respeitos aos fatos e aos conceitos que } \\
\text { se encadeiam no texto, sua organização, as } \\
\text { relações uns com os outros. }\end{array}$ & $\begin{array}{l}\text { Articuladores discursivo-argumentativos } \\
\text { (organização textual e os metadiscursivos) }\end{array}$ \\
\hline Progressão & $\begin{array}{l}\text { Diz respeito à apresentação de novos temas } \\
\text { ou subtemas relacionados ao tema central a } \\
\text { partir da adesão de novos conceitos e } \\
\text { informações aos elementos responsáveis } \\
\text { pela continuidade e pela referenciação. }\end{array}$ & Relação títulos, objetivos e temas \\
\hline Informatividade & $\begin{array}{l}\text { Diz respeito ao grau de previsibilidade da } \\
\text { informação veiculada pelo texto }\end{array}$ & Relação títulos, objetivos e temas \\
\hline $\begin{array}{l}\text { Heterogeneidade enunciativa } \\
\text { (mostrada) }\end{array}$ & $\begin{array}{l}\text { Diz respeito ao vocativo, aos verbos na } \\
\text { primeira pessoa do plural e às frases } \\
\text { retóricas com interrogativas diretas. }\end{array}$ & Interlocução direta \\
\hline
\end{tabular}

Fonte: IFCE.

Temos ciência de que todos os aspectos de composição de um texto poderiam ser pautados para uma avaliação da textualidade de produção didática-academia. Entretanto, apontamos, neste estudo, um recorte do que pode servir como parâmetro inicial para a análise da elaboração de webaulas e, consequentemente, como norte de trabalho para os sujeitos implicados nesta produção colaborativa, mais especificamente o professor conteudista e o designer educacional que trabalham com EaD. 


\section{Considerações FinAIS}

Neste artigo, analisamos os textos-base do material didático-acadêmico produzido para ser publicado no AVA no formato de webaula do curso de Licenciatura em Educação Profissional e Tecnológica (EPCT) do IFCE, bem como as interferências escritas por outros dois sujeitos (designer e revisor textual) que colaboram com o professor na produção do material didático. Vimos que os professores utilizam as operações de textualização - continuidade, progressão, não contradição, articulação, informatividade, heterogeneidade marcada - como principais estratégias textual-discursivas. Tais operações se dão a partir de uma articulação direta com o modo de produção colaborativo do material didático, a perspectiva de reversibilidade discursiva e a dupla audiência prevista pelos sujeitos para o texto. Elas nos dão uma dimensão dos aspectos que são levados em consideração na escrita do texto-base da webaula e, também, dos aspectos que serão avaliados nas etapas seguintes de escrita colaborativa.

Em nosso estudo, vimos que existe, nas interlocuções entre os sujeitos, uma relação entre os diálogos avaliativos - escritos tanto nos comentários quanto no próprio texto-base - e a recursividade de papéis que se dá no processo de produção (ora um sujeito é leitor, ora escritor, ora avaliador do mesmo material didático). Tal relação determina tanto o processo de construção identitária dos sujeitos que escrevem de forma colaborativa quanto marca a autoria do gênero webaula, que é consolidada pelo professor conteudista. Essa relação revela que a construção do texto da webaula ocorre por meio de um movimento contínuo de interferência dos sujeitos em que o professor conteudista, o DE e o revisor deliberadamente respondem e, ao mesmo tempo, passam a palavra ao outro.

Nessa atividade dinâmica de composição escrita, temos dois textos que se intercruzam: o texto didático, referente ao conteúdo da webaula, e o(s) texto(s) avaliativo(s) referente(s) às interlocuções entre os sujeitos presentes nas caixas de comentário nas diversas versões do texto. Por conseguinte, temos duas audiências previstas: uma que se trata dos sujeitos que participam do processo de produção de forma colaborativa (seja avaliando, seja reescrevendo, seja revisando, seja corrigindo, seja retextualizando); outra que se trata dos alunos que estudam por meio do material didático-digital. Essas duas perspectivas sobre o texto e sobre os interactantes organizam toda a transposição didática feita para um texto de cunho acadêmico e didático como a webaula.

Essa construção do texto na cadeia de escrita colaborativa feita a partir da alteridade caracteriza uma atitude metacognitiva por parte dos sujeitos participantes, os quais participam de um jogo de compreensões responsivas. Esse jogo é marcado na avaliação feita pelos sujeitos em cada interlocução e suas ações verbais acontecem de acordo com relação que se estabelece entre interlocutores. Vimos também que os diálogos avaliativos denotam, na escrita colaborativa, o empoderamento de vozes, hierarquização dos sujeitos no que se refere à autoria do texto.

\section{REFERÊNCIAS}

ANTUNES, I. Análise de textos: fundamentos e práticas. São Paulo: Parábola, 2010.

AUTHIER-REVUZ, J. Heterogeneidade(s) enunciativa(s). Cadernos de Estudos Lingüísticos, Campinas, n. 19, p. 25-42, jul./dez. 1990.

CAVAlCANTE, M. M. Os sentidos do texto. São Paulo: Contexto, 2014. 
CAVALCANTE, M. M; CUSTÓDIO FILHO, V; BRITO. M. A. Coerência, referenciação e ensino. São Paulo: Cortez, 2014.

CHAROLLES, M. Introduction aux problèmes de la cohérence des textes: approche théorique et étude des pratiques pédagogiques. Langue Française, n. 38, Enseignement du récit et cohérence du texte. p. 7-41, mai 1978. Disponível em: http://bit.ly/3p4W3ub. Acesso em: 22 mar. 2015.

FIORIN, J. L. Da necessidade da distinção entre texto e discurso. In: BRAIT, B.; SOUZA-E-SILVA, M. C. (org.). Texto ou discurso? São Paulo: Contexto, 2012. p. 145-165.

KOCH, I. V. Introdução à linguística textual. São Paulo: Martins Fontes, 2004.

KOCH, I. V.; ELIAS, M. V. Ler e escrever: estratégias de produção textual. São Paulo: Contexto, 2009.

KOCH, I. V.; ELIAS, M. V. Escrever e argumentar. São Paulo: Contexto, 2016.

MARCUSCHI, L. A. Produção textual, análise de gêneros e compreensão. São Paulo: Parábola, 2008.

MARCUSCHI, L. A. linguistica de texto: o que é e como se faz? São Paulo: Parábola, 2012.

MATÊNCIO, M. de L. M. Atividade de (Re) textualização em práticas acadêmicas: um estudo do resumo. Scripta, v. 6, n. 11, p. 109-122, 2002. Disponível em: https://bit.ly/3qQRbtp. Acesso em: 15 jan. 2019.

VAL, M. da G. C. Redação e textualidade. 2. ed. São Paulo: Martins Fontes, 1999. 